\title{
Temporal posttraumatic limited ocular movement with suspected trapdoor fracture
}

\author{
This article was published in the following Dove Press journal: \\ Clinical Ophthalmology \\ 18 August 2014 \\ Number of times this article has been viewed
}

\author{
Young-Seok Song \\ Harumasa Yokota \\ Haruna Ito \\ Akitoshi Yoshida \\ Department of Ophthalmology, \\ Asahikawa Medical University, \\ Asahikawa, Hokkaido, Japan
}

\begin{abstract}
Trapdoor fractures, or blowout fractures, result from muscle entrapment after orbital floor fractures. The incarcerated muscles may become necrotic because of ischemia; immediate surgery is recommended for symptomatic persistent diplopia or clinical evidence of entrapment. We report a case of spontaneous resolution of diplopia in a patient with a high suspicion of a trapdoor fracture. A 15-year-old girl presented with diplopia after being hit in the eye while playing volleyball. Computed tomography did not show a fractured orbital bone, but the forced duction test was positive when the left eye was pulled forward toward the left. Magnetic resonance imaging was negative for edema and inflammation in the extraocular muscles. With observation only, the diplopia resolved 2 weeks after onset. A negative forced duction test confirmed the resolution. Observation only may be appropriate in cases with posttraumatic limited ocular movement, after imaging has excluded an emergent condition.
\end{abstract}

Keywords: limited eye movement, trauma, abducent disorder, spontaneous remission

\section{Background}

Orbital floor fractures, also known as blowout fractures, are fractures in which the orbital bone is isolated from the orbital floor but with an intact orbital rim. ${ }^{1}$ These fractures often occur during engagement in sports or play, motor vehicle accidents, or assaults. ${ }^{2-4}$ The trapdoor fracture, also called a "white-eyed blowout" is a blowout fracture in which a linear orbital wall fracture occurs. ${ }^{2}$ A flap of bone then is displaced outwardly, and it immediately returns to its original position. ${ }^{3}$ This is caused by muscle entrapment or connective tissue septa after the orbital floor fracture, ${ }^{4,5}$ and without emergent release, the incarcerated muscles may become necrotic because of ischemia. ${ }^{6-8}$ In the chronic phase, fibrosis may also develop from inflammation, causing permanent ocular movement disorders. ${ }^{4,5,8,9}$ For this reason, immediate surgery is often recommended for orbital floor fractures with symptomatic persistent diplopia or clinical evidence of entrapment. ${ }^{7,8,10}$ We report a case of spontaneous resolution of diplopia in a patient with a high suspicion of trapdoor fracture.

\section{Case presentation}

A 15-year-old girl sustained a mild blow to her left eye while playing volleyball and later noticed diplopia with mild pain at the inner canthus, with no nausea or vomiting. She presented to our clinic the day of the injury with esotropia. The Hess chart examination showed an abducent disorder of her left eye (Figure 1A). Both pupils were round and of equal size. The best-corrected visual acuity (BCVA) was 1.2 bilaterally; other ophthalmic examinations showed no abnormalities except for limited ocular movement of the left eye. Since a posttraumatic abducent disorder was observed in the left
Correspondence: Young-Seok Song Department of Ophthalmology, Asahikawa Medical University, Midorigaoka Higashi 2-I-I-I, Asahikawa 078-85I0, Japan

Tel +81166682543

Fax +8I I66 682549

Email ysong@asahikawa-med.ac.jp 
A

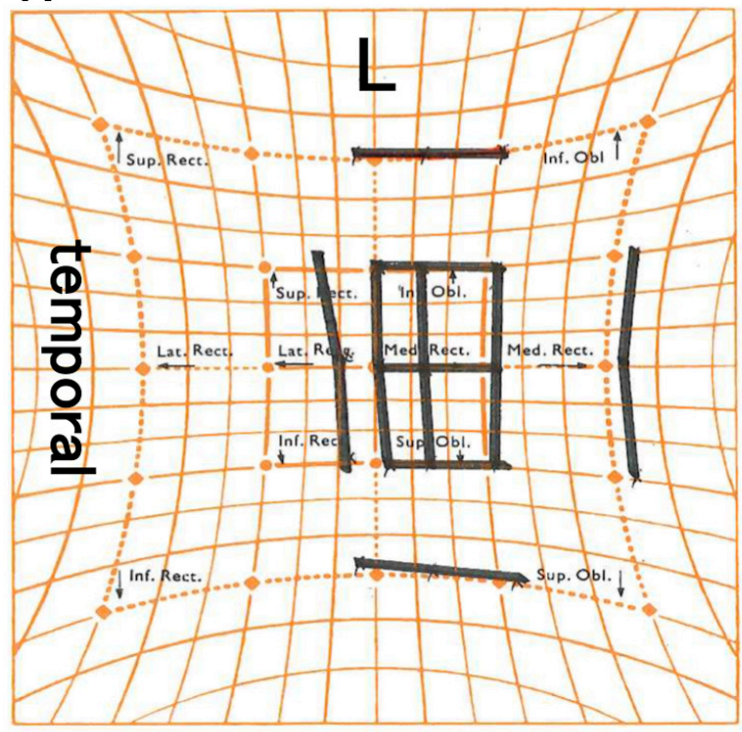

B

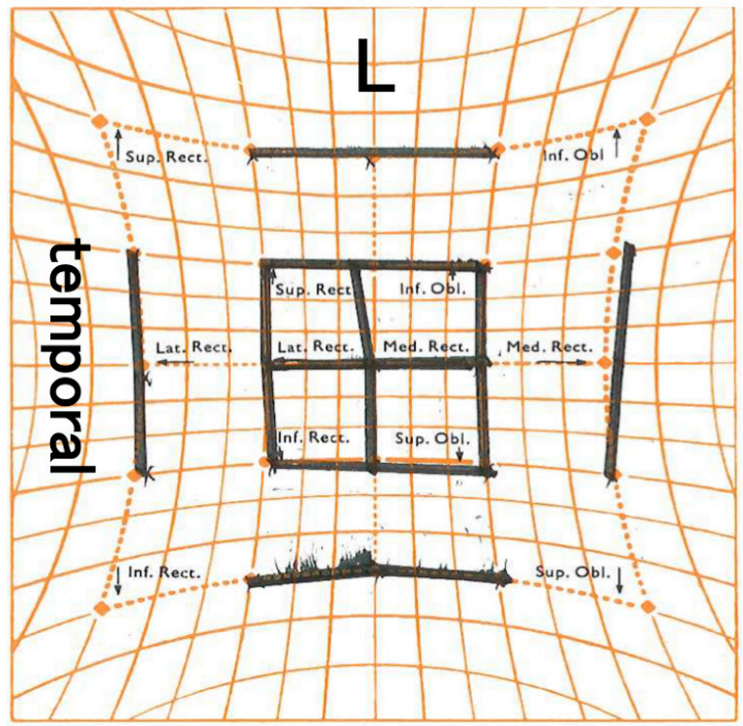

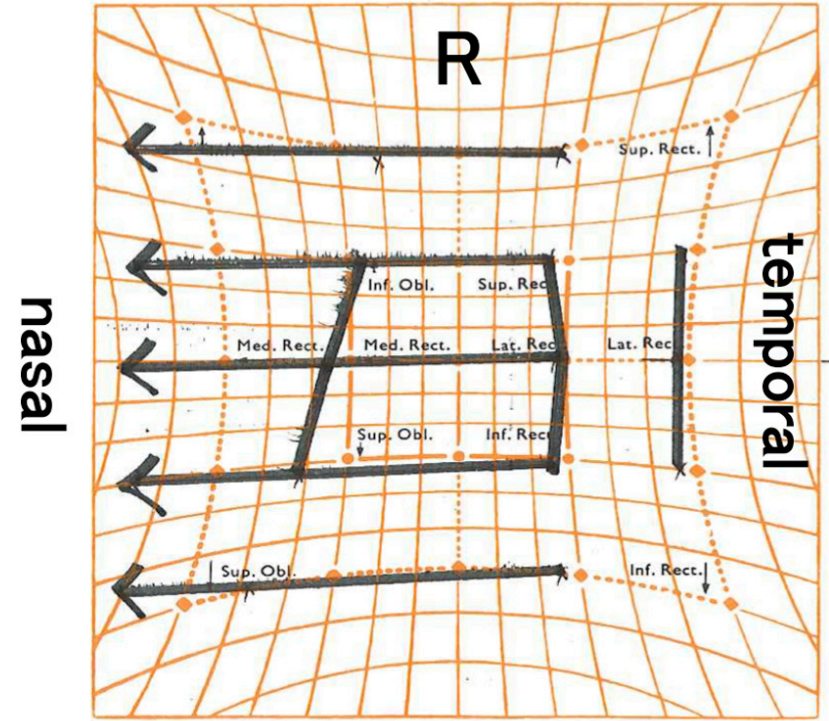

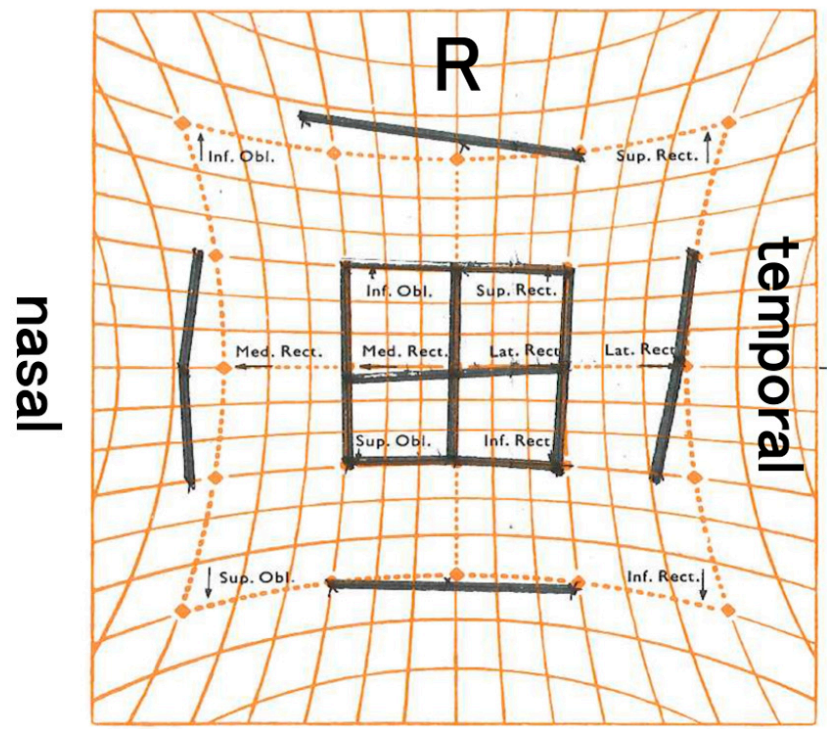

Figure I The Hess chart examination at the initial visit.

Notes: (A) The Hess chart examination at the first clinic visit showed substantially limited abducent of the left eye. (B) The Hess chart examination 2 weeks later shows that the limited abduction of the left eye was fully recovered. Each arrow indicates the direction of action on each extraocular muscles.

Abbreviations: Sup., superior; Inf., inferior; Lat., lateral; Med., medial; Rect., rectus muscle; Obl., oblique muscle.

eye, the Radiodiagnostics Department in our hospital imaged the eye for an orbital floor fracture. However, the thin slice (1 mm) computed tomography (CT) scans were negative, and maxillary sinuses were intact with no fluid or fractures (Figure 2A). To identify paralysis or functional damage, we consulted specialist strabismologists in our department. The forced duction test was performed by them and was unexpectedly positive when the left eye was pulled forward to the left side, indicating the presence of incarceration, with an inapparent orbital bone fracture and suspected trapdoor fracture. Magnetic resonance imaging (MRI), including short tau inversion recovery (STIR) imaging, a modality for fat suppression and enhancement of edema and inflammation in bodily tissues, ${ }^{11}$ was performed to confirm edema and inflammation in the extraocular muscles. The scan was negative for edema and inflammation and other abnormalities (Figure 2B). The Otolaryngology - Head and Neck Surgery Department in our hospital recommended observation without surgery because the visual acuity (VA) was good and imaging showed no fracture, muscle entrapment, edema, or active inflammation. The symptoms remained the same until 2 weeks later, when the patient reported sudden resolution of the diplopia. 
A

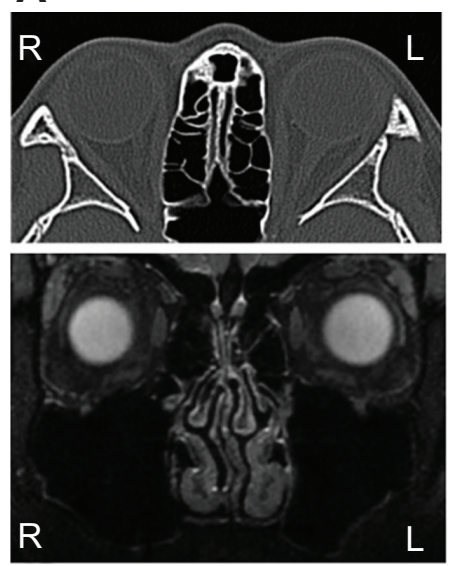

B

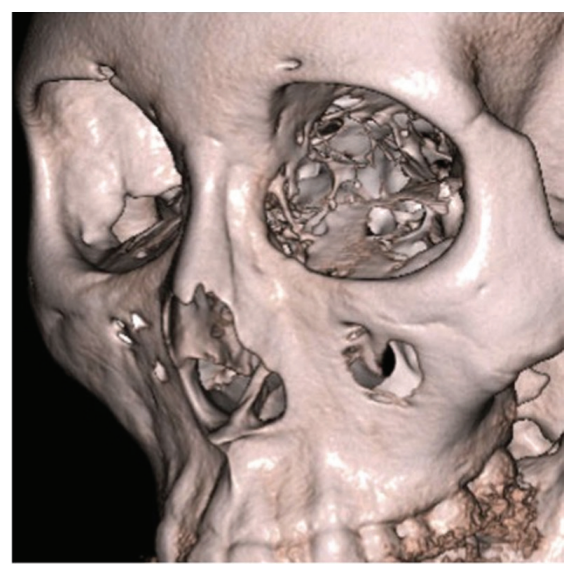

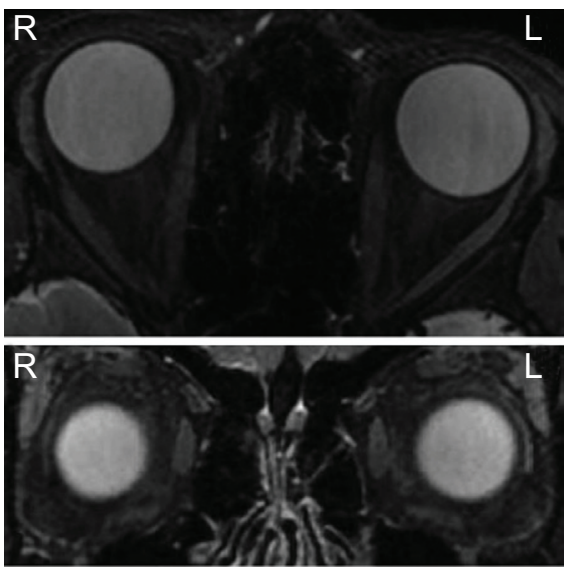

Figure 2 The orbital imaging with $C T$ and $M R I$ at initial visit.

Notes: (A) Orbital computed tomography (CT) images (horizontal section and a constructed image) and magnetic resonance imaging (frontal section) at the first clinic visit showed no apparent orbital fracture or transposition. As well, maxillary sinuses were intact, with no fluid or fractures. (B) Short tau inversion recovery (STIR) magnetic resonance imaging (MRI) of the orbit at the first clinic visit improved visualization of bodily tissues by providing enhanced contrast with fat suppression. ${ }^{20}$ There was no enhanced region in the extraocular muscles or surrounding tissue, indicating there was no orbital edema and/or inflammation.

A Hess chart examination and a forced duction test were normal that day (Figure 1B). Two months later, there were no sequelae, including diplopia.

\section{Discussion}

No apparent objective evidence of orbital fracture was found in this case, although we used a CT with a thin slice $(1 \mathrm{~mm})$. In addition, suspicious symptoms of blowout or entrapment of extraocular muscles, such as the oculocardiac reflex (nausea, vomiting, bradycardia, and syncope) were absent. We also considered psychogenic esotropia in the differential diagnosis, which is concomitant squint without any organic state and caused by a psychogenetic etiology. ${ }^{11}$ However, the patient had limited abduction of her left eye and a positive forced duction test when the left eye was pulled to the left. The patient also reported discomfort of the left inner canthus when the left eye was pulled toward the left, which indicated an organic state but no psychogenic etiology. A CT generally provides excellent bone images and is highly sensitive for imaging orbital floor fractures but is imperfect (sensitivity, $96 \%$; specificity, $71 \%$ ). ${ }^{12} \mathrm{We}$ suspected that the limited movement of the left eye was caused by a trapdoor fracture, despite the absence of an apparent fracture on the $\mathrm{CT}$, ie, when the left eye was hit by the volleyball, the medial orbital wall would likely have sustained a microfracture. Subsequently, orbital tissue might be entrapped in this space.

The indications for immediate surgery for orbital floor fractures are commonly symptomatic persistent diplopia, muscle or soft tissue entrapment on the $\mathrm{CT}$, and positive forced ductions or other clinical evidence of entrapment, enophthalmos ( $>2 \mathrm{~mm}$ at presentation), oculocardiac reflex, fractures comprising greater than $50 \%$ of the orbital floor, or no clinical improvement over several weeks. ${ }^{8-10}$ Most studies have reported that earlier surgical intervention for children with entrapment results in better outcomes than does later intervention, ${ }^{7-9,13-18}$ whereas Criden and Ellis ${ }^{19}$ reported that recovery of extraocular motility was prolonged in children compared with adults, despite early surgical intervention. In addition, numerous possible complications are associated with surgery for orbital floor fractures in children, such as infection, hemorrhage, motility problems (restriction and persistent diplopia), implant-related complications (migration/ extrusion, palpable hardware, autologous graft donor site pain), muscle or optic nerve incarceration or compression, fistula, cyst and mucocele formation, cosmesis, infraorbital dysesthesia, and lacrimal system problems (dacrocystitis, obstruction). ${ }^{9,13,16,17,19}$ In the current case, following an athletic injury, there was no sign of an orbital fracture on the $\mathrm{CT}$, but the patient had diplopia and positive forced duction. Ordinarily, this patient might have been a surgical candidate. However, we chose observation because results showed normal ophthalmic findings, with no ocular motility problems other than diplopia, and she was asymptomatic. In addition, STIR-MRI did not detect any abnormality that might lead to irreversible fibrosis in the extraocular muscles. In fact, the situation resolved completely without any complications, including diplopia.

In conclusion, we had an unusual experience with an orbital trapdoor fracture. Physicians may choose to observe patients without surgery in cases of posttraumatic limited ocular movement, after CT and STIR-MRI have excluded conditions that require emergent care. 


\section{Disclosure}

The authors report no conflicts of interest in this work.

\section{References}

1. Smith B, Regan WF. Blow-out fracture of the orbit; mechanism and correction of internal orbital fracture. Am J Ophthalmol. 1957;44(6): 733-739.

2. Ethunandan M, Evans BT. Linear trapdoor or "white-eye" blowout fracture of the orbit: not restricted to children. Br J Oral Maxillofac Surg. 2011;49(2):142-147.

3. Phan LT, Jordan Piluek W, McCulley TJ. Orbital trapdoor fractures. Saudi J Ophthalmol. 2012;26(3):277-282.

4. Koornneef L, Zonneveld FW. Orbital anatomy, the direct scanning of the orbit in three planes and their bearings on the treatment of motility disturbances of the eye after orbital "blow-out" fractures. Acta Morphol Neerl Scand. 1985;23(3):229-246.

5. Koornneef L. Current concepts on the management of orbital blow-out fractures. Ann Plast Surg. 1982;9(3):185-200.

6. Baek SH, Lee EY. Clinical analysis of internal orbital fractures in children. Korean J Ophthalmol. 2003;17(1):44-49.

7. Sires BS, Stanley RB, Levine LM. Oculocardiac reflex caused by orbital floor trapdoor fracture: an indication for urgent repair. Arch Ophthalmol. 1998;116(7):955-956.

8. Jordan DR, Allen LH, White J, Harvey J, Pashby R, Esmaeli B. Intervention within days for some orbital floor fractures: the white-eyed blowout. Ophthal Plast Reconstr Surg. 1998;14(6):379-390.

9. Egbert JE, May K, Kersten RC, Kulwin DR. Pediatric orbital floor fracture: direct extraocular muscle involvement. Ophthalmology. 2000; 107(10):1875-1879.
10. Burnstine MA. Clinical recommendations for repair of isolated orbital floor fractures: an evidence-based analysis. Ophthalmology. 2002; 109(7):1207-1210; discussion 1210-1211; quiz 1212.

11. Rappaport EA. Anger, apathy and strabismus. Eye Ear Nose Throat Mon. 1959;38(6):473-482.

12. Jank S, Emshoff R, Etzelsdorfer M, Strobl H, Nicasi A, Norer B. Ultrasound versus computed tomography in the imaging of orbital floor fractures. J Oral Maxillofac Surg. 2004;62(2):150-154.

13. Wang NC, Ma L, Wu SY, Yang FR, Tsai YJ. Orbital blow-out fractures in children: characterization and surgical outcome. Chang Gung Med J. 2010;33(3):313-320.

14. Gerbino G, Roccia F, Bianchi FA, Zavattero E. Surgical management of orbital trapdoor fracture in a pediatric population. J Oral Maxillofac Surg. 2010;68(6):1310-1316.

15. Kwon JH, Moon JH, Kwon MS, Cho JH. The differences of blowout fracture of the inferior orbital wall between children and adults. Arch Otolaryngol Head Neck Surg. 2005;131(8):723-727.

16. Yoon KC, Seo MS, Park YG. Orbital trapdoor fracture in children. J Korean Med Sci. 2003;18(6):881-885.

17. Grant JH 3rd, Patrinely JR, Weiss AH, Kierney PC, Gruss JS. Trapdoor fracture of the orbit in a pediatric population. Plast Reconstr Surg. 2002; 109(2):482-489; discussion 490-495.

18. Bansagi ZC, Meyer DR. Internal orbital fractures in the pediatric age group: characterization and management. Ophthalmology. 2000;107(5): 829-836.

19. Criden MR, Ellis FJ. Linear nondisplaced orbital fractures with muscle entrapment. J AAPOS. 2007;11(2):142-147.

20. Bley TA, Wieben O, François CJ, Brittain JH, Reeder SB. Fat and water magnetic resonance imaging. J Magn Reson Imaging. 2010;31(1): $4-18$.
Clinical Ophthalmology

\section{Publish your work in this journal}

Clinical Ophthalmology is an international, peer-reviewed journal covering all subspecialties within ophthalmology. Key topics include: Optometry; Visual science; Pharmacology and drug therapy in eye diseases; Basic Sciences; Primary and Secondary eye care; Patient Safety and Quality of Care Improvements. This journal is indexed on Submit your manuscript here: http://www.dovepress.com/clinical-ophthalmology-journal

\section{Dovepress}

PubMed Central and CAS, and is the official journal of The Society of Clinical Ophthalmology (SCO). The manuscript management system is completely online and includes a very quick and fair peer-review system, which is all easy to use. Visit http://www.dovepress.com/ testimonials.php to read real quotes from published authors. 